\title{
The Assessment and Management of Coronary Artery Disease in Patients with HIV
}

Paul Bhamra-Ariza and Cameron Holloway*

Cameron Holloway, Cardiology Dept, St Vincent's Hospital, Victoria St, Darlinghurst, Australia

\begin{abstract}
HIV is now a chronic treatable disease, with a life expectancy approaching the general population. However, treatments with anti-retroviral medications are associated with metabolic abnormalities and an increased risk of coronary artery disease, leading to a greater incidence of cardiac morbidity and mortality. A contemporary approach to the management of patients with HIV must therefore include aggressive management of cardiovascular risk factors and appropriate screening of cardiovascular disease. This review outlines the pathogenesis of coronary disease in patients with HIV and a modern approach for screening and management.
\end{abstract}

Keywords: Human immunodeficiency virus; Coronary artery disease; Atherosclerosis; Inflammation; screening

Abbreviations: ACS: Acute Coronary Syndrome; CAD: Coronary Artery Disease; cART: combined Combination Antiretroviral Therapy; DAD study: The Data Collection on Adverse Events of Anti-HIV Drugs study; DES: Drug Eluting Stents; HIV: Human Immunodeficiency Virus; MACCE: Major Adverse Cardiac and Cerebrovascular Event; NRTIs: Nucleoside Reverse Transcriptase Inhibitors; NNRTIs: NonNucleoside Reverse Transcriptase Inhibitors; PIs: Protease Inhibitors; SMART: Strategies for Management of Antiretroviral Therapy Trial

\section{Introduction}

Developments in the treatment of Human Immunodeficiency Virus (HIV) have led to improved survival for patients with HIV. Prior to the advent of combined combination antiretroviral therapy (cART), patients were at a significant risk of dying prematurely from opportunistic infections and cardiac disease, including failure. cART has dramatically altered prognosis, with near-normal life expectancy, though is now associated with a high rate of cardiac complications including severe heart failure. Patients with HIV have a higher calculated risk of cardiovascular disease compared to an aged match HIV-negative population [1], which is partly due to an atherogenic lipid profile, insulin resistance from chronic cART, and a higher incidence of traditional risk factors for cardiovascular disease, including smoking, dyslipidemia and diabetes. In addition, HIV itself likely increases the risk of coronary heart disease, partly due to the chronic inflammatory milieu, with even those on anti-retroviral therapy showing elevated inflammatory markers [2]. The object of this review is to explore the potential risks for HIV-associated coronary disease and provide a management strategy for these patients at high risk.

\section{Presentation}

Patients with HIV have a similar spectrum of cardiovascular presentations as non-infected individuals. The most frequent presentation of cardiac disease in patients with HIV is myocardial infarction due to ST elevation, followed by non-ST elevation infarction, then unstable angina [3]. The clinical characteristics of patients with HIV and coronary artery disease (CAD) are well documented [4]. The stereotypical patient is a male between $40-50$ years of age having been diagnosed with HIV for $>8$ years [4]. Often there is a history of smoking, dyslipidaemia, and prior use of cART.

Most patients with HIV are treated conventionally with percutaneous coronary intervention (PCI, $25 \%$ to $76 \%$ ), followed by coronary artery bypass grafting (CABG, $4 \%$ to $18 \%$ ) and medical therapy alone ( $10 \%$ to $20 \%$ ) [4]. There is no difference in Major Adverse Cardiac and Cerebrovascular event (MACCE) and clinical restenosis at 1-year follow up between HIV and non-HIV subjects undergoing treatment for acute coronary syndrome (ACS), but recurrent ACS and urgent PCI is more frequent in HIV-infected patients [3]. However when multiple studies are pooled together and follow up is extended to 2 years, the incidence of acute myocardial infarction in HIV subjects with previous ACS is almost $10 \%$ [5]. The largest retrospective study examining in-patient and one year mortality in subjects with and without HIV after sustaining acute myocardial infarction found no difference in mortality rates. However at 12 months, hospitalizations for episodes of heart failure were significantly more frequent in HIV-infected than in uninfected patients [6]. When percutaneous revascularisation is undertaken, patients with HIV should be considered for implantation of drug eluting stents (DES), to reduce MACE $[7,8]$ including target lesion revascularization and target vessel revascularization after which conventional therapy is dual antiplatelet therapy for a period of 6 to 12 months. Clopidogrel is activated by the CYP2C19 enzyme system, which is inhibited by the non-nucleoside reverse transcriptase inhibitors (NNRTI) etravirine. Although no formal assessment of this interaction has been studied, the combination of etravirine and clopidogrel is not recommended ${ }^{8}$. Recently there has been a move to use more potent antiplatelet agents in the general population following stent implantation. However physicians should be aware of potential interactions between the newer agents such as prasugrel [9] or ticagrelor [10] and ritonavir.

\section{Epidemiology}

Observational data from large cohort studies have confirmed the

*Corresponding author: Cameron Holloway, Cameron Holloway, Cardiology Dept, St Vincent's Hospital, Victoria St, Darlinghurst, Australia, Tel: 028038 1080; E-mail: camholloxford@gmail.com

Received December 21, 2013; Accepted January 29, 2014; Published February 11,2014

Citation: Bhamra-Ariza P, Holloway C (2014) The Assessment and Management of Coronary Artery Disease in Patients with HIV. J AIDS Clin Res 5: 283. doi:10.4172/2155-6113.1000283

Copyright: (C) 2014 Bhamra-Ariza P, et al. This is an open-access article distributed under the terms of the Creative Commons Attribution License, which permits unrestricted use, distribution, and reproduction in any medium, provided the original author and source are credited. 
association of HIV and coronary disease. Administrative data from claim records for HIV-infected and uninfected individuals from the California Medicaid population found the incidence of coronary heart disease, including acute myocardial infarction and coronary atherosclerosis, was increased in subjects infected with HIV, with a relative risk [RR] of 6.76 (95\% CI 3.36-13.58) for men and 2.47 (95\% CI 1.23-4.95) for women [11]. A recent meta-analysis examining the risk of cardiovascular disease in patients with HIV without treatment found the relative risk of CVD was $61 \%$ higher compared to HIV uninfected patients [12]. The French Hospital Database on HIV found that an HIV-1 RNA level $>50$ copies/mL, a low CD4 T-cell nadir, and a high current CD8 T-cell count were significantly associated with an increased risk of myocardial infarction [13]. The CD4 T-cell nadir/ current CD8 T-cell count ratio was a slightly better predictor of the risk of myocardial infarction [13].

\section{Aetiology of Increased CV Risk}

The underlying pathophysiological mechanisms resulting in the increased risk of ischaemic heart disease in patients with HIV are complex and likely a combination of traditional as well as novel risk factors (Figure 1).

\section{Antiretroviral therapy}

The association between cART and cardiovascular risk is well established [13-17]. There are three principal classes of antiretroviral therapy: protease inhibitors (PIs), nucleoside reverse transcriptase inhibitors (NRTIs), and non-nucleoside reverse transcriptase inhibitors (NNRTIs). The Data Collection on Adverse Events of Anti-HIV Drugs (DAD) Study [14] found the incidence of MI increased with increasing exposure to combination antiretroviral therapy, particularly in the presence of PIs [15]. The incidence of MI increased from 1.5 to 6 events per 1000 person years in HIV-infected patients after six years of PI exposure, with an adjusted relative risk of 1.16 (95\% CI 1.10-1.23) for every year of PI exposure [15].

In addition, recent use of NRTIs abacavir and did anosine have been shown to increase the risk of MI by $90 \%$ and $49 \%$, respectively, as compared to subjects whom have never used or who have ceased taking these medications more than 6 months previously [17]. However, the data surrounding abacavir and the risk of MI is further complicated

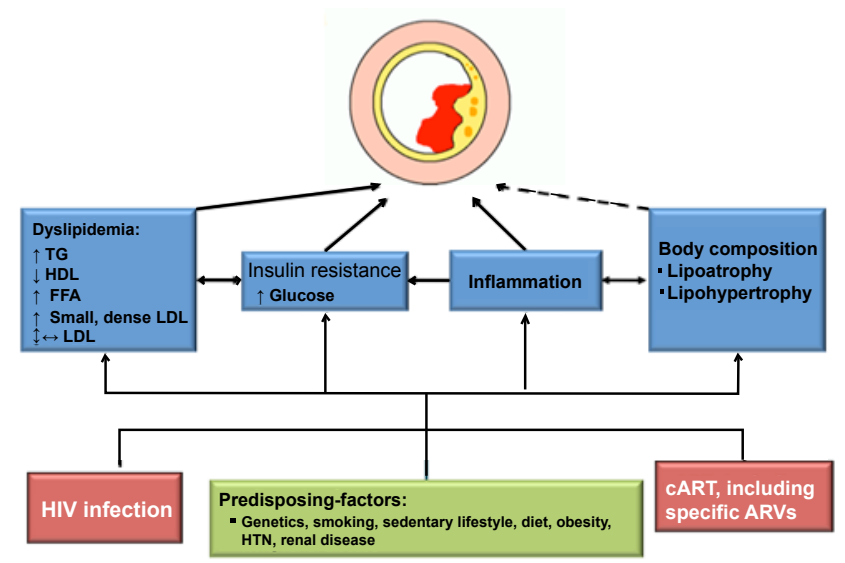

Figure 1: Pathogenesis of increased risk of coronary artery disease in patients with HIV. (cART, combined highly active combination antiretroviral therapy ARV, antiretroviral; FFA, free fatty acids; HDL, high-density lipoprotein; HTN, hypertension; LDL, low-density lipoprotein; TG, triglycerides). by conflicting conclusions of several meta-analyses. The largest metaanalysis to date consisting of 26 randomised control trials (9868 subjects) found no association between abacaviruse and MI risk [18]. A significant limitation was the short follow-up period of 1.43 personyears in the abacavir group and 1.49 person-years in the non-abacavir group. Given rates of myocardial infarction were relatively infrequent, and the follow up was short it is possible that the study did not have the power to detect differential risk between the two treatments. In contrast, exposure to NNRTIs has not been associated with an increase in the risk of myocardial infarction $[14,16]$. Cumulative exposure to indinavir or lopinavir-ritonavir has been shown to be associated with an increased risk of myocardial infarction, whilst there is no significant association between myocardial infarction risk and longer exposure to nelfinavir or saquinavir [16], though these latter agents are not commonly prescribed.

The paradox, however, is that continuous cART exposure is associated with a reduced risk of myocardial infarction. The 3-year risk of myocardial infarction among subjects in the DAD study who received cART was estimated to be around 2\% [19]. The reduction in absolute risk of myocardial infarction over 3 years if HIV subjects stopped cART was estimated to be less than $1.5 \%$. In contrast there is a 3 -year risk of AIDS or death of $5-10 \%$ in people receiving cART; a rate of $25-35 \%$ in people not receiving cART, and $22-29 \%$ in people receiving cART if they were to cease treatment [19]. A pivotal study, Strategies for Management of Antiretroviral Therapy (SMART) trial demonstrated discontinuation of ART resulted in a paradoxical higher risk of myocardial infarction. This study randomised HIV patients to either continuous use of antiretroviral therapy or episodic use of antiretroviral therapy [20]. Episodic use of cART, with withdrawal of therapy until CD4+ counts decreased to less than 250 per cubic millimeter, followed by the re-introduction of therapy until the CD4+ count increased to more than 350 per cubic millimeter was associated with a higher risk of fatal or non-fatal CVD (hazard ratio of $1.6,96 \% \mathrm{CI}$ 1.0-2.5) [20].

\section{HIV and coronary artery disease risk}

HIV itself is thought to cause a pro-atherogenic state via the interplay of multiple mechanisms [21]. Chronic immune activation and inflammation are characteristic of untreated HIV infection. Elevated levels of CRP and IL6 in HIV are associated with a higher incidence of coronary artery disease [22,23]. In addition a pro-coagulant state, with increased levels of d-dimer, fibrinogen, and other markers of coagulation (e.g. factor VIII and von Willebrand factor) is thought to contribute to an increased cardiovascular risk in HIV patients [21]. The SMART Trial demonstrated elevations in hs-CRP and IL-6 occurred during periods of cART interruption, which itself was associated with an increased incidence of fatal and non-fatal cardiovascular events, supporting the hypothesis that hs-CRP and IL- 6 were predictive of CVD risk in HIV-infected patient $[23,24]$. However other trials have failed to changes in CRP and IL-6 concentrations following cART interuuprtion [25].

Currently there are no anti-inflammatory medications available that reduce inflammation and result in lowering cardiovascular events. Preliminary in vivo and in vitro work suggested that pentoxifylline might reduce vascular inflammation and improve endothelial function in HIV patients. However a randomised study placebo controlled trial found no significant differences in flow mediated dilatation of the brachial artery and an unexpected increase in inflammatory biomarkers [26]. Statins have been shown to have an anti-inflammatory effect independent of lipid lowering [27]. There is controversy regarding 
whether statins and their ability to inhibit HIV replication $[28,29]$. However a recent study suggests they have an effect on markers of immune activation. Researched found there was a reduction in CD4+ and CD8+ T-lymphocytes of $2.5-5.0 \%$ [30]. Whether this reduction translated into any clinical benefit remains unanswered.

\section{Dyslipidaemia}

Infection with HIV results in a modest dyslipidaemic state, independent of ART, by causing a decline in the cardio-protective high-density lipoprotein cholesterol (HDL-C) [31]. The majority of the dyslipidaemic profile, however, results from cART [32]. Protease Inhibitors are associated withincreased VLDL, LDL-cholesterol and triglycerides. Within the protease inhibitor drug class, total cholesterol and triglyceride levels are highest in patients treated with ritonavir, either alone or in combination with another protease inhibitor, and lowest in patients receiving saquinivir [33]. Changes in lipid levels associated with NRTIs are relatively mild compared to protease inhibitors or nonnucleoside reverse transcriptase inhibitors. Zidovudine and stavudine have the most unfavorable outcomes on lipid profile from this drug group in comparison to tenofovir [34,35]. The NNRTIN evirapineis associated with a more favourable lipid profile than other ART drugs, with increased HDL. Comparison of cART regimes containing Nevirapine or Efavirenz have shown significant increases in HDL-c, along with increases in total cholesterol, nonHDL-c, triglycerides, and LDL-c. The proportional increase of HDL-c was larger in the Nevirapine treatment group compared to the Efavirenz treatment group, while the proportional increase of total cholesterol, non-HDL-c, and TGs was significantly smaller [36]. In contrast, Etravirine, a newer NNRTI, has little effect on patient's lipid profiles [37].

\section{Insulin resistance/metabolic syndrome}

Patients with HIV have a high prevalence of abnormalities in glucose metabolism. Insulin resistance has been observed in 25\%-30\% of HIVinfected patients, whilst the incidence of diabetes mellitus among this population is reported to be $2 \%-8 \%$, depending on the definition of diabetes used [38-40]. HIV infection itself does not significantly increase the risk of diabetes [41]. Abnormalities in glucose metabolism are associated with cART, and increase with cumulative exposure [42]. Additionally, patients co-infected with HIV and Hepatitis C have an increased incidence of diabetes and insulin resistance [43]. As with the general population, development of diabetes in patients with HIV is associated with central adiposity and specific diabetogenic drugs, including thiazide diuretics, steroids and high dose beta-blockers. HIV-associated lipodystrophy is characterised by loss of body fat in the limbs and face, which can occur with or without fat accumulation in the abdominal or dorsocervical region. About $55 \%$ of treated-HIV patients report change in body fat or its distribution after cART [44]. HIV-associated lipodystrophy is most strongly associated PI and NRTI use, as well as with advanced disease, age, and treatment duration. PIs impair glucose homeostasis by causing irreversible inhibition of the Glut4 glucose transporter, which is responsible for movement of glucose into fat cells, cardiac and skeletal muscle [45]. Insulin resistance is also strongly associated with NRTIs and is thought to be secondary to mitochondrial toxicity [46]. As a result of mitochondrial toxicity increased levels of circulating free fatty acids occur which can induce hyper insulinaemia and insulin resistance [47].

\section{Assessing Risk In HIV}

Traditional risk factors for cardiovascular disease such as age, smoking, diabetes and dyslipidemia, contributes similar burden of cardiovascular risk in HIV-infected and uninfected populations [48]. However, compared to age matched controls, patients with HIV have a higher prevalence of smoking and higher rates of dyslipidaemia, hypertension and insulin resistance. When assessing CV risk, conventional multivariate models are often used to calculate CHD risk - however it is widely acknowledged that there is only moderate concordance between different cardiac risk scores. Previously designed models may not be directly applicable to the HIV population. The average age of HIV-infected subjects is lower than the age distribution in the populations for whom conventional CVD risk prediction models were developed. These models only take into account traditional risk factors for CVD and do not account for novel risk factors such as inflammation, immune activation, cART or HIV itself. For example, The Framingham Risk score underestimates cardiovascular risk in HIV patients who smoke [49]. Among European, US, and Australian participants in DAD study taking antiretrovirals, Framingham risk scores under estimated actual MI incidence ( 9 observed MIs versus 5.5 predicted). But among antiretroviral-naive people, Framingham risk scores over estimated actual incidence ( 3 observed MIs versus 7.6 predicted) [49]. Current guidelines do not take into account the increased burden of CVD in the HIV population. The type of optimum stress test used to detect myocardial ischemia is yet to be determined in low or intermediate risk patients. Patients with acute coronary syndromes, however, are high-risk and should be referred directly for invasive coronary arteriography, as per guidelines for the general population [50].

Conventional exercise stress testing has been shown to have a sensitivity of approximately $60 \%$ and specificity of $70 \%$ in the non-HIV population and is generally considered less specific in women than in men even after correction for post-test referral bias [51,52]. Therefore, conventional exercise ECG stress is no longer recommended, regardless of HIV status. We believe that patients with HIV and an intermediate risk of coronary disease should be best investigated with stress echocardiography or coronary CT. This is our personal view and not based on international guidelines or outcome trials. The identification and quantification of a coronary artery calcium scoring provides prognostic information in patients with coronary artery disease. However, this tool may not be particularly useful to the HIV population, as soft plaques are more frequently seen in this population [53-55]. CT coronary angiography has demonstrated a high prevalence of coronary atherosclerosis in asymptomatic HIV with low cardiovascular risk as compared to matched non-HIV subjects [56]. Furthermore CT is able to noninvasively assess plaque morphology [57]. Low plaque attenuation, positive remodeling (plaque segment diameter more than reference segment diameter), and/or the presence of spotty calcification adherent to plaque - have been shown in non-HIV-infected populations to characterize plaques in patients with acute coronary syndrome [58] and to prospectively predict plaque rupture [59]. CT angiography in HIV subjects have confirmed an increased prevalence of plaque among HIVinfected patients versus controls with similar traditional cardiovascular risk factors [55]. In a HIV population CT is cost effective with a high sensitivity specificity to identify non-calcified, potentially vulnerable, plaques [60]. Early identification of plaque also facilitates aggressive risk factor modification. In patients where risk factors are already treated, stress echocardiography is a good alternative.

\section{Management of Risk Factors}

Given the higher incidence of premature CAD in HIV subjects, efforts should be focused on improving modifiable risk factors such as smoking, cocaine use, hypertension, dyslipidaemia and disordered 
glucose metabolism. Regular exercise and dietary intervention have been shown to result in beneficial effects on lipid profiles and improve peripheral insulin sensitivity [61-63]. We therefore suggest a multidisciplinary approach, involving HIV physicians, general practitioners, specialist nurses, endocrinologists and cardiologists be used in the prevention and treatment of cardiovascular complications in subjects with HIV.

\section{Blood pressure}

Hypertension occurs in up to one third of patients with HIV and is associated with insulin resistance and the metabolic syndrome [64]. However there is controversy as to whether the prevalence is any higher when compared to non-HIV subjects [65]. Current practice suggestive the use of conventional guidelines; including lifestyle modification and pharmacotherapy should $\mathrm{SBP}>140$ or $\mathrm{DBP}>90 \mathrm{mmHG}$ (especially if the 10 -year CVD risk is $>20 \%$ ) [66].

\section{Smoking cessation}

Smoking is highly prevalent in the HIV population with studies consistently reporting at least a 2 to 3 fold increased rate of smoking in HIV subjects compared to the general population $[67,68]$. Furthermore the effects of smoking on the risk of MI in HIV are greater than other CVD risk factors $[15,69]$. The beneficial effect of smoking cessation has been demonstrated in HIV patients. Rates of myocardial infarction are reduced from an almost 4 fold increased relative risk compared to never smokers among patients who are in the first year following smoking cessation to just over 2 fold greater relative risk among those who have stopped smoking more than 3 years previously [70].

\section{Dyslipidaemia}

General approach: Despite the increased risk of coronary disease and high prevalence of dyslipidaemia, guidelines for dyslipidaemia in HIV subjects are based on those developed for the non-HIV population [71]. Recent guidelines regarding the initiation of statin therapy favor the use of a new Pooled Cohort Equations to estimate the atherosclerotic cardiovascular risk (ASCVD risk) rather than specific LDL-C and /or non-HDL-C targets [72]. Statin therapy has been recommended in 4 treatment groups in the non HIV population - those with clinical ASCVD, patients with primary elevation of LDL-C $>190 \mathrm{mg} / \mathrm{L}$, patients with diabetes and those an estimated ASCVD score $>7.5 \%$. Patients with HIV are not only likely to have conventional risk factors for CAD, but also novel risk factors including heightened inflammation, immune activation, ART or HIV itself. It is reasonable to use caution when initiating and up-titrating statin therapy in patients with HIV due to the high chance of drug interactions [72]. Recent guidelines acknowledge high intensity statin treatment reduces ASCVD risk better than moderate or lower intensity statin therapy albeit with a higher risk of drug interactions [72]. Therefore statin therapy should be optimized to the maximum appropriate dosage without causing adverse side effects.

An important consideration is the association with anti-retroviral therapy and dyslipidaemia and, where appropriate, changing classes. However this risk reduced antiviral potency. The use of statins with antiretroviral agents may be complicated by drug interactions, since statins, PIs, and NNRTIs are all metabolized via cytochrome P450 (CYP450) 3A4 enzymes. In addition, lipid responses to lipid lowering drug therapy may be modestly attenuated in HIV-infected patients as compared to the general population [73].

A fasting lipid profile should be performed for all HIV-infected patients. If the lipid profile is normal, repeat testing should be performed every 6-12 months, with more frequent measurements in patients with obesity, diabetes, fat redistribution, or a family history of dyslipidemia. Therapeutic lifestyle changes such as dietary modification, exercise and weight loss are effective methods in treating dyslipidaemia.

Lipid lowering therapy (Table 1): Statins are recommended as first line treatment for elevated LDL-C levels or for elevated nonHDL-C levels when triglyceride levels are $200-500 \mathrm{mg} / \mathrm{dL}$ (2.3-5.6 $\mathrm{mmol} / \mathrm{l}$ ) [74]. Most statins are, to varying degrees, substrates for the CYP3A4 enzyme system and therefore signs of statin toxicity should be monitored. Liver function tests should be assessed at baseline and 4-6 weeks after therapy has been initiated. Simvastatin and lovastatin should not be prescribed with PIs because of the high risk of harmful interactions [75]. Atorvastatin should be used with caution when coadministered with PIs and administered at lowest possible dosing [75]. Although Rosuvastatin is not metabolised by the CYP3A4 enzyme it should be commenced cautiously at a low dose when combined with PIs. Rosuvastatin has been shown to be more potent in lowering LDL-C and TG than pravastatin in patients with HIV without causing any severe adverse events [76]. Recently there have been concerns that statins may increase the incidence of diabetes [77]. The INTREPID trial confirmed pitavastatin was superior to pravastatin in terms of LDL reductions, and neither statin had significant effects on glucose metabolism [78]. Although Pitavastatin undergoes minimal cytochrome P450 there is potential for interaction between pitavastatin and lopinavir/ritonavir and therefore this combination is not recommended [79]. The NNRTIs nevirapine and efavirenz are potent inducers of the CYP3A4 enzyme

\begin{tabular}{|c|c|}
\hline Starting Dose & Comments \\
\hline $10 \mathrm{mg}$ & \multirow{2}{*}{ Check for antibiotic (I.E. Clarithromycin) and } \\
\hline $5 \mathrm{mg}$ & \\
\hline $20 \mathrm{mg}$ & $2^{\text {nd }}$ Line (lower potency) \\
\hline $1 \mathrm{mg}$ & $3^{\text {rd }}$ Line (lower potency) \\
\hline \multicolumn{2}{|c|}{ NOT recommended for co-administration with Pls or delarvidine } \\
\hline $1.2 \mathrm{~g}-3.6 \mathrm{~g}$ & No adjustment required \\
\hline $145 \mathrm{mg}$ & No adjustment required \\
\hline $10 \mathrm{mg}$ & No adjustment required \\
\hline $\begin{array}{l}500 \mathrm{mg} \\
\text { (extended release- dose) }\end{array}$ & Maximum of $2,000 \mathrm{mg} /$ day over 4 to 8 weeks \\
\hline $10 \mathrm{mg}$ & No adjustment required \\
\hline
\end{tabular}

Monitor ALT/CK if combustion statin/fibrate, $\uparrow$ risk of side effects. Dose reduce if renal dysfunction Used in combination, or as monotherapy if statin is contraindicated.

Avoid as first-line therapy in patients receiving Pls or in patients with lipodystrophy

Table 1: Recommended lipid lowering therapy in patients with HIV. 
system, which results in potentially reduced lipid lowering potency of statins [80]. Delavirdine is a potent inhibitor of CYP3A4 and should not be given in combination with simvastatin or lovastatin, whereas it can be given cautiously with other statins [74].

Fibrates are useful in treating PI-associated hypertriglyceridemia and should be considered in patients with triglycerides $>500 \mathrm{mg} / \mathrm{dL}$ $(>5.6 \mathrm{mmol} / \mathrm{L})[74,81,82]$. The combination of fibrates and statins can be effectively used when patients with mixed dyslipidemia have not responded appropriately in the presence of monotherapy. For example, the combination of fenofibrate and pravastatin improves lipid levels with minimal side effects [83]. However even with combination therapy as described above, most patients with mixed dyslipidemia remain outside of current recommended targets. Certain combinations should be avoided such as gemfibrozil and statins due to high rates of muscle toxicity [84].

Niacin in combination with statin therapy can be used to further reduce LDL-C and non-HDL-C levels while increasing HDL-C levels [85]. However to date no randomised control trial has shown any prognostic benefit of using this drug $[86,87]$. The addition of niacin to statin therapy may be safer than use of a statin-fibrate combination, but it has not been studied in HIV-infected subjects. Insulin resistance has been noted after commencing niacin and therefore it should be avoided as first-line therapy in patients receiving PIs or in patients with lipodystrophy [74]. It is recommended that subjects treated with niacin undergo a glucose-tolerance test, particularly when lipodystrophy or traditional risk factors for type 2 diabetes mellitus are present [74]. Ezetemibe does not inhibit or induce cytochrome P450 and is safe to use with statin therapy in HIV patients with mixed dyslipidemia [88].

Managing insulin resistance: Patients with HIV should be screened for diabetes at the time of HIV diagnosis, at the initiation and 3-6 months following cART therapy. Simple lifestyle modifications such as diet and exercise have been shown to help reduce the incidence of type 2 diabetes [89]. Metformin is commonly used as a first line agent in type 2 diabetics and improves insulin resistance in subjects with HIV lipodystrophy [90]. It is contraindicated in patients taking NRTIs because of an increased risk of lactic acidosis [91]. Thiazolidinediones improve insulin resistance and increase limb fat, and so may be useful for treating lipodystrophy in HIV patients, whereas patients with truncal obesity are more likely to benefit from metformin [92]. Other oral anti-diabetic agents such as sulfonylureas and meglitinides have not been studied in the HIV population. Insulin therapy may be required in type 2 diabetes when glycaemic control cannot be achieved with the oral treatments alone. Advantages of insulin therapy include the lack of interactions between insulin and cART and its anabolic properties, which may be useful in HIV/diabetes patients who have a low BMI.

\section{Conclusion}

The pathogenesis of coronary artery disease in HIV is multifactorial, with increased cardiac events due to chronic inflammation, metabolic complications of cART, as well as contributions from traditional risk factors (Table 2). Coronary plaque in HIV has higher risk characteristics, including soft, vulnerable plaque. Conventional risk scores underestimate the prevalence of CAD in the HIV population and the addition of HIV and cART to a model of established AMI risk factors may helpful. Given the complex interplay of metabolic abnormalities and drug interactions, a multidisciplinary approach, involving HIV physicians, general practitioners, specialist nurses, endocrinologists and cardiologists are required to prevent and treat cardiovascular complications. Smoking cessation remains the most
Take home messages

- Conventional CVD risk prediction models underestimate risk in patients with HIV

- Smoking cessation is the most powerful risk factor for IHD in patients with HIV

- Lipid abnormalities should be screened for every 6 months and aggressively controlled

- Glucose abnormalities need screening every 3-6 months

- If cardiovascular risk is greater than $7.5 \%$ over 10 years, CTCA or stress echo recommended for screening of coronary artery disease

Table 2: Conclusions and take home messages.

powerful modifiable risk factor [93] and patients should be given support and encouragement to stop smoking. Additional aggressive risk factor screening and management includes diet modification, exercise and regular lipid and glucose assessment to prevent cardiovascular disease. Whilst evidenced based guidelines are awaited, aggressive risk factor modification and screening are recommended to decrease the high cardiovascular morbidity and mortality seen in patients with HIV.

\section{References}

1. Kaplan RC, Kingsley LA, Sharrett AR, Li X, Lazar J, et al. (2007) Ten-year predicted coronary heart disease risk in HIV-infected men and women. Clin Infect Dis 45: 1074-1081.

2. Freiberg MS, Chang CC, Kuller LH, Skanderson M, Lowy E, et al. (2013) HIV infection and the risk of acute myocardial infarction. JAMA Intern Med 173: 614-622.

3. Boccara F, Mary-Krause M, Teiger E, Lang S, Lim P, et al. (2011) Acute coronary syndrome in human immunodeficiency virus-infected patients: characteristics and 1 year prognosis. Eur Heart J 32: 41-50.

4. Boccara F, Lang S, Meuleman C, Ederhy S, Mary-Krause M, et al. (2013) HIV and coronary heart disease: time for a better understanding. J Am Coll Cardiol 61: $511-523$.

5. D'Ascenzo F, Cerrato E, Biondi-Zoccai G, Moretti C, Omedè P, et al. (2012) Acute coronary syndromes in human immunodeficiency virus patients: a metaanalysis investigating adverse event rates and the role of antiretroviral therapy. Eur Heart J 33: 875-880.

6. Lorgis L, Cottenet J, Molins G, Benzenine E, Zeller M, et al. (2013) Outcomes After Acute Myocardial Infarction in HIV-Infected Patients: Analysis of Data From a French Nationwide Hospital Medical Information Database. Circulation 127: $1767-1774$.

7. Ren X, Trilesskaya M, Kwan DM, Nguyen K, Shaw RE, et al. (2009) Comparison of Outcomes Using Bare Metal Versus Drug-Eluting Stents in Coronary Artery Disease Patients With and Without Human Immunodeficiency Virus Infection. Am J Cardiol 104: 216-222.

8. Kakuda TN, Schöller-Gyüre M, Hoetelmans RM (2011) Pharmacokinetic interactions between etravirine and non-antiretroviral drugs. Clin Pharmacokinet 50: $25-39$.

9. Daali Y, Ancrenaz V, Bosilkovska M, Dayer P, Desmeules J (2011) Ritonavir inhibits the two main prasugrel bioactivation pathways in vitro: a potential drugdrug interaction in HIV patients. Metabolism 60: 1584-1589.

10. Zhou D, Andersson TB, Grimm SW (2011) In vitro evaluation of potentia drug-drug interactions with ticagrelor: cytochrome $\mathrm{P} 450$ reaction phenotyping, inhibition, induction, and differential kinetics. Drug Metab Dispos 39: 703-710.

11. Currier JS, Taylor A, Boyd F, Dezii CM, Kawabata H, et al. (2003) Coronary heart disease in HIV-infected individuals. J Acquir Immune Defic Syndr 33: 506512 .

12. Islam FM, Wu J, Jansson J, Wilson DP (2012) Relative risk of cardiovascular disease among people living with HIV: a systematic review and meta-analysis. HIV Med 13: 453-468.

13. Lang S, Mary-Krause M, Simon A, Partisani M, Gilquin J, et al. (2012) HIV replication and immune status are independent predictors of the risk of myocardial infarction in HIV-infected individuals. Clin Infect Dis 55: 600-607.

14. Friis-Møller N, Sabin CA, Weber R, d'Arminio Monforte A, El-Sadr WM, et al. (2003) Combination antiretroviral therapy and the risk of myocardial infarction. N Engl J Med 349: 1993-2003. 
15. DAD Study Group, Friis-Møller N, Reiss P, Sabin CA, Weber R, et al. (2007) Class of antiretroviral drugs and the risk of myocardial infarction. $\mathrm{N}$ Engl J Med 356: 1723-1735

16. Worm SW, Sabin C, Weber R, Reiss P, El-Sadr W, et al. (2010) Risk of myocardial infarction in patients with HIV infection exposed to specific individual antiretroviral drugs from the 3 major drug classes: the data collection on adverse events of anti-HIV drugs (D:A:D) study. J Infect Dis 201: 318-330.

17. D:A:D Study Group, Sabin CA, Worm SW, Weber R, Reiss P, et al. (2008) Use of nucleoside reverse transcriptase inhibitors and risk of myocardial infarction in HIV-infected patients enrolled in the D:A:D study: a multi-cohort collaboration. Lancet 371: 1417-1426.

18. Ding X, Andraca-Carrera E, Cooper C, Miele P, Kornegay C, et al. (2012) No association of abacavir use with myocardial infarction: findings of an FDA metaanalysis. J Acquir Immune Defic Syndr 61: 441-447.

19. Law M, Friis-Møller N, Weber R, Reiss P, Thiebaut R, et al. (2003) Modelling the 3 -year risk of myocardial infarction among participants in the Data Collection on Adverse Events of Anti-HIV Drugs (DAD) study. HIV Med 4: 1-10.

20. Strategies for Management of Antiretroviral Therapy (SMART) Study Group, ElSadr WM, Lundgren J, Neaton JD, Gordin F, et al. (2006) CD4+ count-guided interruption of antiretroviral treatment. N Engl J Med 355: 2283-2296.

21. Baker JV, Lundgren JD (2011) Cardiovascular implications from untreated human immunodeficiency virus infection. Eur Heart J 32: 945-951.

22. Triant VA, Meigs JB, Grinspoon SK (2009) Association of C-reactive protein and HIV infection with acute myocardial infarction. J Acquir Immune Defic Syndr 51: 268-273.

23. Kuller LH, Tracy R, Belloso W, De Wit S, Drummond F, et al. (2008) Inflammatory and coagulation biomarkers and mortality in patients with HIV infection. PLoS Med 5: e203.

24. Triant VA, Lee H, Hadigan C, Grinspoon SK (2007) Increased acute myocardial infarction rates and cardiovascular risk factors among patients with human immunodeficiency virus disease. J Clin Endocrinol Metab 92: 2506-2512.

25. Calmy A, Gayet-Ageron A, Montecucco F, Nguyen A, Mach F, et al. (2009) HIV increases markers of cardiovascular risk: results from a randomized, treatment interruption trial. AIDS 23: 929-939.

26. Gupta SK, Mi D, Dubé MP, Saha CK, Johnson RM, et al. (2013) Pentoxifylline, inflammation, and endothelial function in HIV-infected persons: a randomized, placebo-controlled trial. PLoS One 8: e60852.

27. Ridker PM, Danielson E, Fonseca FA, Genest J, Gotto AM Jr, et al. (2008) Rosuvastatin to prevent vascular events in men and women with elevated C-reactive protein. N Engl J Med 359: 2195-2207.

28. Moncunill G, Negredo E, Bosch L, Vilarrasa J, Witvrouw M, et al. (2005) Evaluation of the anti-HIV activity of statins. AIDS 19: 1697-1700.

29. Amet T, Nonaka M, Dewan MZ, Saitoh Y, Qi X, et al. (2008) Statin-induced inhibition of HIV-1 release from latently infected U1 cells reveals a critical role for protein prenylation in HIV-1 replication. Microbes Infect 10: 471-480.

30. Ganesan A, Crum-Cianflone N, Higgins J, Qin J, Rehm C, et al. (2011) High dose atorvastatin decreases cellular markers of immune activation without affecting HIV-1 RNA levels: results of a double-blind randomized placebo controlled clinical trial. J Infect Dis 203: 756-764.

31. Duprez DA, Kuller LH, Tracy R, Otvos J, Cooper DA, et al. (2009) Lipoprotein particle subclasses, cardiovascular disease and HIV infection. Atherosclerosis 207: 524-529.

32. Badiou S, Merle De Boever C, Dupuy AM, Baillat V, Cristol JP, et al. (2003) Decrease in LDL size in HIV-positive adults before and after lopinavir/ritonavircontaining regimen: an index of atherogenicity? Atherosclerosis 168: 107-113.

33. Fontas E, van Leth F, Sabin CA, Friis-Møller N, Rickenbach M, et al. (2004) Lipid profiles in HIV-infected patients receiving combination antiretroviral therapy: are different antiretroviral drugs associated with different lipid profiles? $\mathrm{J}$ Infect Dis 189: 1056-1074.

34. Gallant JE, DeJesus E, Arribas JR, Pozniak AL, Gazzard B, et al. (2006) Tenofovir DF, emtricitabine, and efavirenz vs. zidovudine, lamivudine, and efavirenz for HIV. N Engl J Med 354: 251-260.

35. Gallant JE, Staszewski S, Pozniak AL, DeJesus E, Suleiman JM, et al. (2004) Efficacy and safety of tenofovir DF vs stavudine in combination therapy in antiretroviral-naive patients: a 3-year randomized trial. JAMA 292: 191-201.
36. van Leth F, Phanuphak P, Stroes E, Gazzard B, Cahn P, et al. (2004) Nevirapine and efavirenz elicit different changes in lipid profiles in antiretroviral-therapynaive patients infected with HIV-1. PLoS Med 1: e19.

37. Girard PM, Campbell TB, Grinsztejn B, Hartikainen J, Rachline A, et al. (2012) Pooled week 96 results of the phase III DUET-1 and DUET-2 trials of etravirine: further analysis of adverse events and laboratory abnormalities of special interest. HIV Med 13: 427-435.

38. Brown TT, Cole SR, Li X, Kingsley LA, Palella FJ, et al. (2005) Antiretroviral therapy and the prevalence and incidence of diabetes mellitus in the multicenter AIDS cohort study. Arch Intern Med 165: 1179-1184.

39. Wand H, Calmy A, Carey DL, Samaras K, Carr A, et al. (2007) Metabolic syndrome, cardiovascular disease and type 2 diabetes mellitus after initiation of antiretroviral therapy in HIV infection. AIDS 21: 2445-2453.

40. Justman JE, Benning L, Danoff A, Minkoff H, Levine A, et al. (2003) Protease inhibitor use and the incidence of diabetes mellitus in a large cohort of HIVinfected women. J Acquir Immune Defic Syndr 32: 298-302.

41. Butt AA, McGinnis K, Rodriguez-Barradas MC, Crystal S, Simberkoff M, et al. (2009) HIV infection and the risk of diabetes mellitus. AIDS 23: 1227-1234.

42. De Wit S, Sabin CA, Weber R, Worm SW, Reiss P, et al. (2008) Incidence and risk factors for new-onset diabetes in HIV-infected patients: the Data Collection on Adverse Events of Anti-HIV Drugs (D:A:D) study. Diabetes Care 31: 12241229.

43. Jain MK, Aragaki C, Fischbach L, Gibson S, Arora R, et al. (2007) Hepatitis $C$ is associated with type 2 diabetes mellitus in HIV-infected persons without traditional risk factors. HIV Med 8: 491-497.

44. Cabrero E, Griffa L, Burgos A; HIV Body Physical Changes Study Group (2010) Prevalence and impact of body physical changes in HIV patients treated with highly active antiretroviral therapy: results from a study on patient and physician perceptions. AIDS Patient Care STDS 24: 5-13.

45. Noor MA, Seneviratne T, Aweeka FT, Lo JC, Schwarz JM, et al. (2002) Indinavir acutely inhibits insulin-stimulated glucose disposal in humans: a randomized, placebo-controlled study. AIDS 16: F1-8.

46. Brinkman K, Smeitink JA, Romijn JA, Reiss $P$ (1999) Mitochondrial toxicity induced by nucleoside-analogue reverse-transcriptase inhibitors is a key factor in the pathogenesis of antiretroviral-therapy-related lipodystrophy. Lancet 354 1112-1115.

47. Hadigan C, Borgonha S, Rabe J, Young V, Grinspoon S (2002) Increased rates of lipolysis among human immunodeficiency virus-infected men receiving highly active antiretroviral therapy. Metabolism 51: 1143-1147.

48. Currier JS, Lundgren JD, Carr A, Klein D, Sabin CA, et al. (2008) Epidemiological evidence for cardiovascular disease in HIV-infected patients and relationship to highly active antiretroviral therapy. Circulation 118: e29-35.

49. Law MG, Friis-Møller N, El-Sadr WM, Weber R, Reiss P, et al. (2006) The use of the Framingham equation to predict myocardial infarctions in HIV-infected patients: comparison with observed events in the D:A:D Study. HIV Med 7: 218-230.

50. Task Force Members, Montalescot G, Sechtem U, Achenbach S, Andreotti F, et al. (2013) 2013 ESC guidelines on the management of stable coronary artery disease: the Task Force on the management of stable coronary artery disease of the European Society of Cardiology. Eur Heart J 34: 2949-3003.

51. Kwok Y, Kim C, Grady D, Segal M, Redberg R (1999) Meta-analysis of exercise testing to detect coronary artery disease in women. Am J Cardiol 83: 660-666.

52. Greulich S, Bruder O, Parker M, Schumm J, Grün S, et al. (2012) Comparison of exercise electrocardiography and stress perfusion CMR for the detection of coronary artery disease in women. J Cardiovasc Magn Reson 14: 36.

53. Fitch KV, Lo J, Abbara S, Ghoshhaira B, Shturman L, et al. (2010) Increased coronary artery calcium score and noncalcified plaque among HIV-infected men: relationship to metabolic syndrome and cardiac risk parameters. J Acquir Immune Defic Syndr 55: 495-499.

54. Fitch KV, Srinivasa S, Abbara S, Burdo TH, Williams KC, et al. (2013) Noncalcified coronary atherosclerotic plaque and immune activation in HIVinfected women. J Infect Dis 208: 1737-1746.

55. Zanni MV, Abbara S, Lo J, Wai B, Hark D, et al. (2013) Increased coronary atherosclerotic plaque vulnerability by coronary computed tomography angiography in HIV-infected men. AIDS 27: 1263-1272. 
56. d'Ettorre G, Francone M, Mancone M, Ceccarelli G, Ascarelli A, et al. (2012) Significant coronary stenosis detected by coronary computed angiography in asymptomatic HIV infected subjects. J Infect 64: 82-88

57. Motoyama S, Sarai M, Narula J, Ozaki Y (2013) Coronary CT angiography and high-risk plaque morphology. Cardiovasc Interv Ther 28: 1-8.

58. Motoyama S, Kondo T, Sarai M, Sugiura A, Harigaya H, et al. (2007) Multislice computed tomographic characteristics of coronary lesions in acute coronary syndromes. J Am Coll Cardiol 50: 319-326.

59. Nakanishi K, Fukuda S, Shimada K, Ehara S, Inanami H, et al. (2012) Nonobstructive low attenuation coronary plaque predicts three-year acute coronary syndrome events in patients with hypertension: multidetector computed tomographic study. J Cardiol. 59: 167-175

60. Nolte JE, Neumann T, Manne JM, Lo J, Neumann A, et al. (2013) Costeffectiveness analysis of coronary artery disease screening in HIV-infected men. Eur J Prev Cardiol.

61. Lindegaard B, Hansen T, Hvid T, van Hall G, Plomgaard P, et al. (2008) The effect of strength and endurance training on insulin sensitivity and fat distribution in human immunodeficiency virus-infected patients with lipodystrophy. J Clin Endocrinol Metab 93: 3860-3869.

62. Thöni GJ, Fedou C, Brun JF, Fabre J, Renard E, et al. (2002) Reduction of fat accumulation and lipid disorders by individualized light aerobic training in human immunodeficiency virus infected patients with lipodystrophy and/or dyslipidemia. Diabetes Metab 28: 397-404

63. Lazzaretti RK, Kuhmmer R, Sprinz E, Polanczyk CA, Ribeiro JP (2012) Dietary intervention prevents dyslipidemia associated with highly active antiretrovira therapy in human immunodeficiency virus type 1-infected individuals: a randomized trial. J Am Coll Cardiol 59: 979-988.

64. Gazzaruso C, Bruno R, Garzaniti A, Giordanetti S, Fratino P, et al. (2003) Hypertension among HIV patients: prevalence and relationships to insulin resistance and metabolic syndrome. J Hypertens 21: 1377-1382.

65. Jericó C, Knobel H, Montero M, Sorli ML, Guelar A, et al. (2005) Hypertension in HIV-infected patients: prevalence and related factors. Am J Hypertens 18: 1396-1401.

66. Mancia G, Fagard R, Narkiewicz K, Redon J, Zanchetti A, et al. (2013) 2013 $\mathrm{ESH} / \mathrm{ESC}$ guidelines for the management of arterial hypertension: the Task Force for the Management of Arterial Hypertension of the European Society of Hypertension (ESH) and of the European Society of Cardiology (ESC). Eur Heart J 34: 2159-2219.

67. Helleberg M, Afzal S, Kronborg G, Larsen CS, Pedersen G, et al. (2013) Mortality attributable to smoking among HIV-1-infected individuals: a nationwide, population-based cohort study. Clin Infect Dis 56: 727-734.

68. Tesoriero JM, Gieryic SM, Carrascal A, Lavigne HE (2010) Smoking among HIV positive New Yorkers: prevalence, frequency, and opportunities for cessation. AIDS Behav 14: 824-835.

69. Lifson AR, Neuhaus J, Arribas JR, van den Berg-Wolf M, Labriola AM, et al. (2010) Smoking-related health risks among persons with HIV in the Strategies for Management of Antiretroviral Therapy clinical trial. Am J Public Health 100: 1896-1903.

70. Petoumenos K, Worm S, Reiss P, de Wit S, d'Arminio Monforte A, et al. (2011) Rates of cardiovascular disease following smoking cessation in patients with HIV infection: results from the D:A:D study( $\left(^{*}\right)$. HIV Med 12: 412-421.

71. Expert Panel on Detection, Evaluation, and Treatment of High Blood Cholesterol in Adults (2001) Executive Summary of The Third Report of The National Cholesterol Education Program (NCEP) Expert Panel on Detection, Evaluation, And Treatment of High Blood Cholesterol In Adults (Adult Treatment Panel III). JAMA 285: 2486-2497.

72. Stone NJ, Robinson J, Lichtenstein AH, Bairey Merz CN, Lloyd-Jones DM, et al. (2013) 2013 ACC/AHA Guideline on the Treatment of Blood Cholesterol to Reduce Atherosclerotic Cardiovascular Risk in Adults: A Report of the American College of Cardiology/American Heart Association Task Force on Practice Guidelines. J Am Coll Cardiol.

73. Silverberg MJ, Leyden W, Hurley L, Go AS, Quesenberry CP Jr, et al. (2009) Response to newly prescribed lipid-lowering therapy in patients with and without HIV infection. Ann Intern Med 150: 301-313.

74. Dubé MP, Stein JH, Aberg JA, Fichtenbaum CJ, Gerber JG, et al. (2003)
Guidelines for the evaluation and management of dyslipidemia in human immunodeficiency virus (HIV)-infected adults receiving antiretroviral therapy: recommendations of the HIV Medical Association of the Infectious Disease Society of America and the Adult AIDS Clinical Trials Group. Clin Infect Dis 37: 613-627.

75. Fichtenbaum CJ, Gerber JG, Rosenkranz SL, Segal Y, Aberg JA, et al. (2002) Pharmacokinetic interactions between protease inhibitors and statins in HIV seronegative volunteers: ACTG Study A5047. AIDS 16: 569-577.

76. Aslangul E, Assoumou L, Bittar R, Valantin MA, Kalmykova O, et al. (2010) Rosuvastatin versus pravastatin in dyslipidemic HIV-1-infected patients receiving protease inhibitors: a randomized trial. AIDS 24: 77-83.

77. Carter AA, Gomes T, Camacho X, Juurlink DN, Shah BR, et al. (2013) Risk of incident diabetes among patients treated with statins: population based study. BMJ 346: $\{2610$

78. Sponseller CA, Morgan R, Campbell S, Kryzhanovski V, Kartman C, et al. (2013) Pitavastatin $4 \mathrm{mg}$ Provides Superior LDL-C Reduction vs. Pravastatin $40 \mathrm{mg}$ Over 12 weeks in HIV-Infected Adults with Dyslipidemia, the INTREPID Trial. Journal of Clinical Lipidology 7: 260.

79. Dubé MP, Cadden JJ (2011) Lipid metabolism in treated HIV Infection. Best Pract Res Clin Endocrinol Metab 25: 429-442.

80. von Moltke LL, Greenblatt DJ, Granda BW, Giancarlo GM, Duan SX, et al (2001) Inhibition of human cytochrome P450 isoforms by nonnucleoside reverse transcriptase inhibitors. J Clin Pharmacol 41: 85-91.

81. Calza L, Manfredi R, Chiodo F (2002) Use of fibrates in the management of hyperlipidemia in HIV-infected patients receiving HAART. Infection 30: 26-31.

82. Visnegarwala F, Maldonado M, Sajja P, Minihan JL, Rodriguez-Barradas MC et al. (2004) Lipid lowering effects of statins and fibrates in the management of HIV dyslipidemias associated with antiretroviral therapy in HIV clinical practice. J Infect 49: 283-290.

83. Aberg JA, Zackin RA, Brobst SW, Evans SR, Alston BL, et al. (2005) A randomized trial of the efficacy and safety of fenofibrate versus pravastatin in HIV-infected subjects with lipid abnormalities: AIDS Clinical Trials Group Study 5087. AIDS AIDS Res Hum Retroviruses 21: 757-767.

84. Davidson MH, Armani A, McKenney JM, Jacobson TA (2007) Safety considerations with fibrate therapy. Am J Cardiol 99: 3C-18C.

85. Dubé MP, Wu JW, Aberg JA, Deeg MA, Alston-Smith BL, et al. (2006) Safety and efficacy of extended-release niacin for the treatment of dyslipidaemia in patients with HIV infection: AIDS Clinical Trials Group Study A5148. Antivir Ther 11: 1081-1089.

86. HPS2-THRIVE Collaborative Group (2013) HPS2-THRIVE randomized placebo-controlled trial in 25673 high-risk patients of ER niacin/laropiprant: trial design, pre-specified muscle and liver outcomes, and reasons for stopping study treatment. Eur Heart J 34: 1279-1291.

87. AIM-HIGH Investigators, Boden WE, Probstfield JL, Anderson T, Chaitman $\mathrm{BR}$, et al. (2011) Niacin in patients with low HDL cholesterol levels receiving intensive statin therapy. N Engl J Med 365: 2255-2267.

88. Chow D, Chen H, Glesby MJ, Busti A, Souza S, et al. (2009) Short-term ezetimibe is well tolerated and effective in combination with statin therapy to treat elevated LDL cholesterol in HIV-infected patients. AIDS 23: 2133-2141.

89. Knowler WC, Barrett-Connor E, Fowler SE, Hamman RF, Lachin JM, et al (2002) Reduction in the incidence of type 2 diabetes with lifestyle intervention or metformin. N Engl J Med 346: 393-403.

90. Hadigan C, Corcoran C, Basgoz N, Davis B, Sax P, et al. (2000) Metformin in the treatment of HIV lipodystrophy syndrome: A randomized controlled trial. JAMA 284: 472-477.

91. Worth L, Elliott J, Anderson J, Sasadeusz J, Street A, et al. (2003) A cautionary tale: fatal lactic acidosis complicating nucleoside analogue and metformin therapy. Clin Infect Dis 37: 315-316.

92. Grinspoon S (2007) Use of thiazolidinediones in HIV-infected patients: what have we learned? J Infect Dis 195: 1731-1733.

93. Rotger M, Glass TR, Junier T, Lundgren J, Neaton JD, et al. (2013) Contribution of Genetic Background, Traditional Risk Factors, and HIV-Related Factors to Coronary Artery Disease Events in HIV-Positive Persons. Clin Infect Dis 57: $112-121$. 